\title{
Continuous Multiple Vertebral Compression Fractures in Multiple Myeloma Patient
}

\author{
Sang Moon Hong, Tae Wan Kim, Kwan Ho Park \\ Department of Neurosurgery, Seoul Veterans Hospital, Seoul, Korea
}

Multiple myeloma is a B-cell origin tumor characterized by hypercalcemia, osteolytic bony lesions, and pathologic fractures. Back pain is one of the most common presenting symptoms of multiple myeloma and about $60 \%$ of patients have vertebral involvement at the time of diagnosis7). Minimally invasive surgeries such as vertebroplasty and kyphoplasty are effective to relieve pain and improve the quality of life when a compression fracture occurs in multiple myeloma patients. We report a case of continuous multiple compression fractures associated with multiple myeloma. We should check for the possibility of pathologic vertebral fractures resulting from multiple myeloma in non-osteoporotic compression fracture patients, and especially in cases of continuous fracture occurring in relatively non-elderly patients, even though a history of trauma may be present.

Key Words: Multiple myeloma $\cdot$ Compression fracture $\cdot$ Vertebroplasty

\section{INTRODUCTION}

Spinal osteolytic lesions are associated with hematologic malignancy and intensive corticosteroid use. Most of the hematologic malignancies are multiple myeloma. Multiple myeloma is a B-cell malignancy, commonly involving skeletal complications. Multiple myeloma accounts for $1 \%$ of adult malignancies and has an annual incidence of 3 to 4 per 100,000 persons in the United States, with a peak age of occurrence in the midsixties. Multiple myeloma is a neoplasm of plasma cells characterized by monoclonal proliferation of plasma cells in bone marrow, infiltration of adjacent tissue and occasionally multiple organs, and production of an immunoglobulin (usually monoclonal $\operatorname{IgG}$ or IgA). Common presenting symptoms of multiple myalgia include bone pain (especially back pain), fatigue (typically caused by anemia), pathologic fracture, weight loss, paresthesia, and fever. Up to $30 \%$ of patients are asymptomatic at diagnosis.

Minimally invasive surgical treatments such as vertebroplasty and kyphoplasty are effective and safe in the manage-

- Received: January 30, 2012 - Revised: March 24, 2012

- Accepted: March 23, 2012

Corresponding Author: Tae Wan Kim, MD

Department of Neurosurgery, Seoul Veterans Hospital, 27 lljasan-gil,

Gangdong-gu, Seoul 134-791, Korea

Tel: +82-2-2225-1363, Fax: + 82-2-2225-4152

E-mail: euro3399@naver.com ment of myelomatous vertebral fracture ${ }^{1,4,8)}$. In local recurrences, vertebroplasty can be executed before radiation therapy, thus synergizing its delayed analgesic action on pain ${ }^{11}$. Delayed injection of cement is safer and more effective in cases of osteolysis or fracture of the posterior vertebral wall ${ }^{2}$. Major spinal surgery is less effective in patients with multiple myeloma due to poor bone quality and median survival time.

\section{CASE REPORT}

A 62-year-old male was admitted to the hospital with a lower back pain, pain in both lower extremities, and numbness that occurred 5 months earlier. He had slipped and fallen 2 months earlier and the back pain had since become aggravated. $\mathrm{He}$ had a history for hypertension, type 2 diabetes mellitus, angina pectoris, and asthma treated with oral medication. Neurologic examination revealed subjective lower extremity weakness and hypoesthesia on both sides. Other abnormalities of neurologic examination were not found. Other than his erythrocyte sedimentation rate of $27 \mathrm{~mm} / \mathrm{hr}$, C-reactive protein of $12 \mathrm{mg} /$ $\mathrm{dL}$, and albumin level of $3.3 \mathrm{~g} / \mathrm{dL}$, the patient's laboratory values on admission were normal. However, his hemoglobin was reduced from 16 to $12 \mathrm{~g} / \mathrm{dL} 3$ months later.

Radiographic studies including 1.5 Tessler magnetic resonance imaging (MRI) and computed tomography (CT) of his lumbar spine were performed on admission. MRI and CT showed mild canal stenosis of L 4-5, but other meaningful abnor- 
mal findings were not found (Fig. 1). The spinal canal stenosis of L 4-5 existed in an MRI of the lumbar spine conducted 2 years earlier, and there was no change in the degree of stenosis. Bone mineral density showed osteopenia (mean T-score was - 2.3). We prescribed analgesics to relieve pain, and had no reason to suspect a secondary vertebral compression fracture. Despite medication with analgesics for 2 months, the lower back pain was aggravated and the patient complained of gait difficulty due to back pain. An MRI of the lumbar spine was performed again and showed an L1 compression fracture (Fig. 2), and therefore, L1 vertebroplasty was performed; however, patient's pain did not improve. On an MRI of the thoracolumbar spine taken one month later, T10, L1, and $\mathrm{L} 3$ compression fractures were shown, and on an MRI of the whole spine 3 months later, T6, T9, T10, L1, L2, L3, L4, and L5 compression fractures were shown (Fig. 3).

Vertebroplasty of T9, T10, L2, and L4 vertebral bodies (Fig. 4) and a bone biopsy of the T9 body were performed by vertebroplasty needle during the vertebroplasty procedure and the patient's lower back pain was relieved. On histological

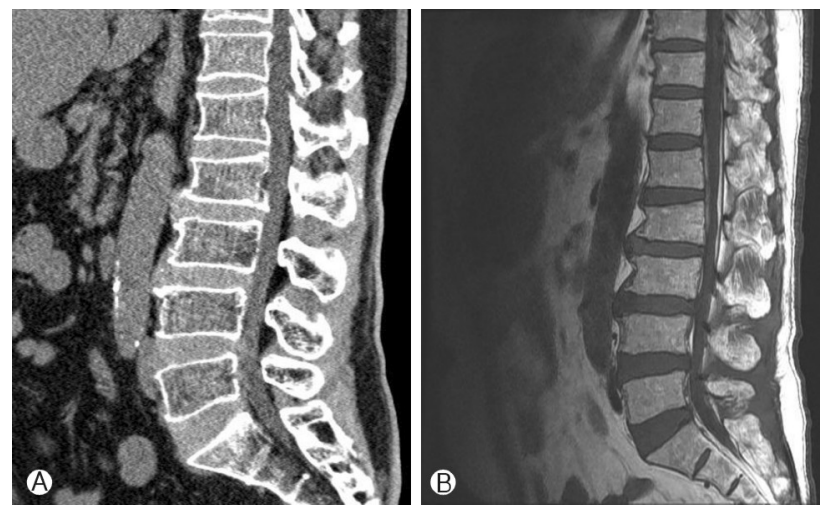

Fig. 1. Computed tomography (A) and magnetic resonance image (B) shows no recent compression fracture at admission.
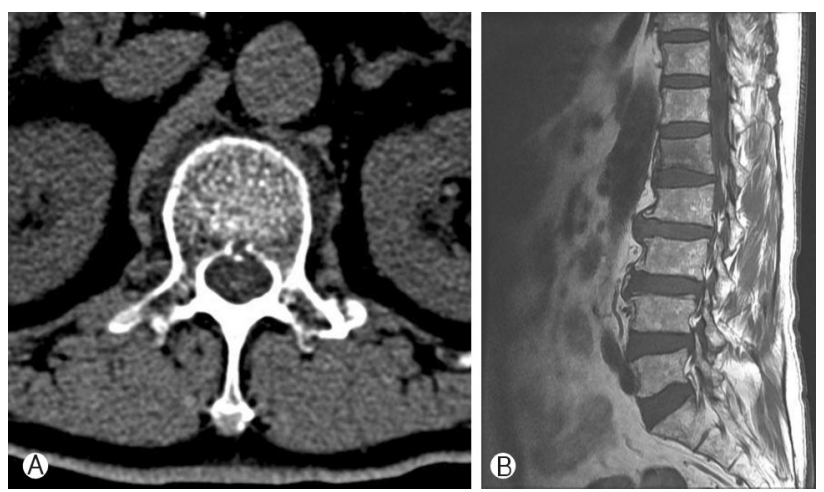

Fig. 2. Two months later, axial image shows cortical disruption on vertebral body (A) and hypodense signal change of LI vertebral body on $\mathrm{T} 1$ weighted sagittal image (B). examination, an obtained specimen revealed infiltration of atypical plasma cells. Immunohistochemical analysis revealed that the plasma cells expressed CD56 (Fig. 5), and also demonstrated monotypic expression of lambda light chain.

Tumor markers (CEA, PSA, CA 19-9, CA-125, and AFP) were demonstrated to be within normal range. On serum protein electrophoresis, an M-spike was present in the gamma globulin fraction, and the concentration of M-spike was 1.10 $\mathrm{g} / \mathrm{dL}$. Serum immunoelectrophoresis and immunofixation electrophoresis revealed monoclonal gammopathy immunoglobulin A (IgA), lambda type. On a quantitative immunoglobulin test,

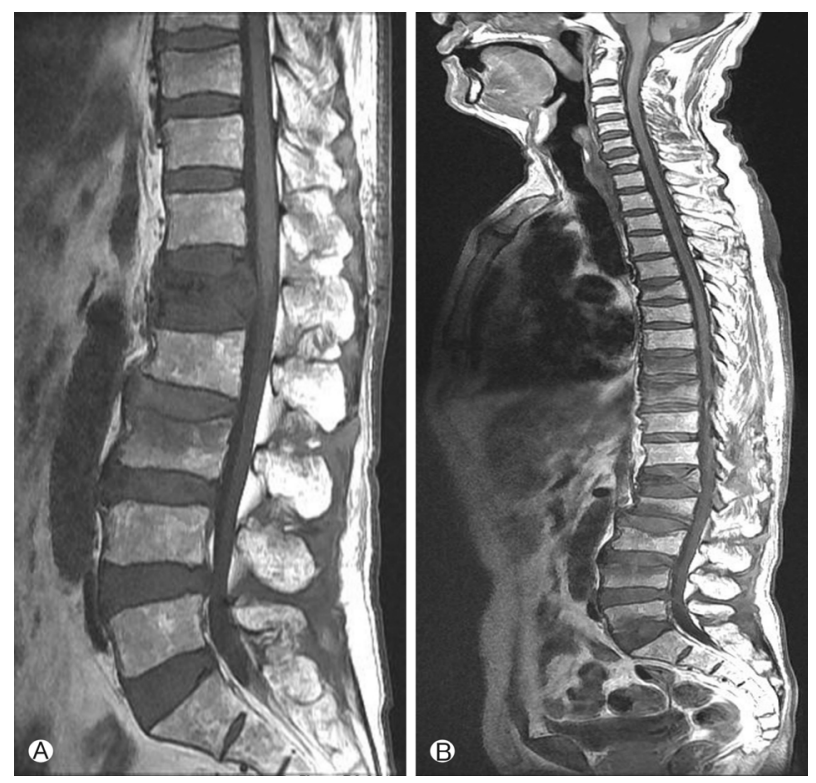

Fig. 3. Three months later after admission, magnetic resonance image shows newly developed compression fracture on T10, L3 vertebral bodies and decrease of vertebral height on L1 (A). Followup study (six months later after admission) shows continuous multiple compression fractures (B).

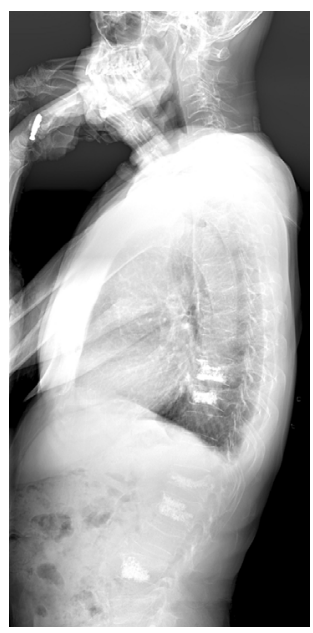

Fig. 4. Vertebroplasty was performed on multiple vertebral bodies (T9, T10, L2, and (4). 

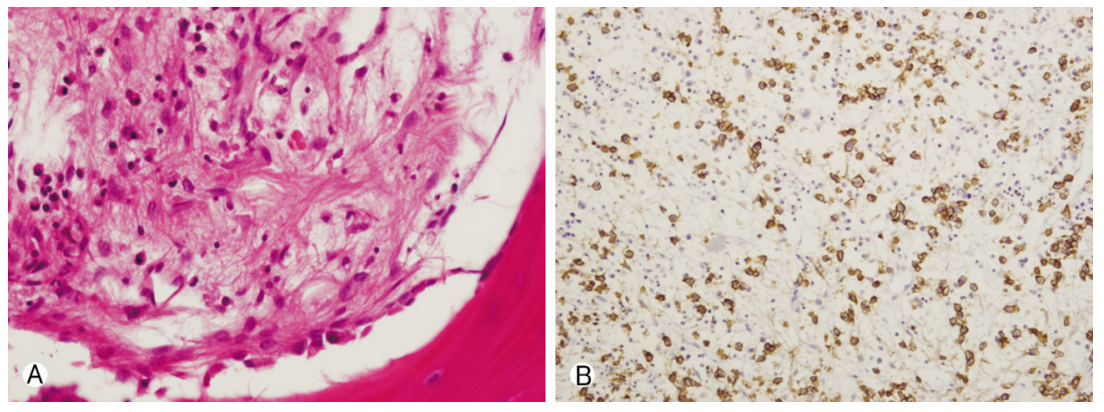

Fig. 5. The pathologic specimen reveals the infiltration of abnormal plasma cells with Russel bodies (H\&E, x400) (A). Immunohistochemistry reveals that CD56 has strong positivity in plasma cells (B). the immunoglobulin $\mathrm{G}$ level was $5.11 \mathrm{~g} / \mathrm{L}$ (normal range is 7 to $16 \mathrm{~g} / \mathrm{L}$ ), the IgA level wa $16.1 \mathrm{~g} / \mathrm{L}$ (normal range is 0.7 to $4 \mathrm{~g} / \mathrm{L}$ ), and the immunoglobulin $\mathrm{M}$ level was $<0.17 \mathrm{~g} / \mathrm{L}$ (nor mal range is 0.4 to $23 \mathrm{~g} / \mathrm{L}$ ).

The above-mentioned results of bone biopsy, electrophoresis, immunoelectrophoresis, and immunofixation electrophoresis proved the diagnosis of multiple myeloma.

The patient was referred to another hospital, where he received VAD (vincristine, Adriamycin, and dexamethasone) chemotherapy 4 times and bone marrow transplantation. The Mspike then decreased from 1.10 to $0.22 \mathrm{~g} / \mathrm{dL}$ on serum protein electrophoresis. The patient is still alive without developing symptoms one year after diagnosis of multiple myeloma.

\section{DISCUSSION}

Primary osteoporosis is responsible for about $85 \%$ of vertebral compression fractures and the remaining 15\% are associated with secondary osteoporosis and neoplasms ${ }^{13)}$.

Patients that suffer bone or back pain in spite of symptomatic treatment for more 2-4 weeks need further evaluation for multiple myeloma and other diseases, including polymyalgia rheumatica, hyperparathyroidism, vitamin D deficiency, and bone metastasis. In case of multiple myeloma, the laboratory findings usually show anemia, thrombocytopenia and neutropenia. Also, the patients sometimes complain fatigue and depressive mood due to hypercalcemia. So, we must be concerned about laboratory findings. Multiple myeloma has a variable appearance on bone scanning. When we meet the compression fractures without hot uptake in bone scanning, more evaluations are needed. Early detection and management will be needed in rapidly progressing multiple myeloma patients ${ }^{14)}$.

If multiple myeloma is suspected, for diagnosis, it is necessary to demonstrate M-proteins in either serum or urine, to prove the presence of $\geq 10 \%$ bone marrow clonal plasma cells, and to observe the clinical manifestations of the disease. The amount of myeloma cell mass can be predicted from the extent of bone lesions, the hemoglobin level, serum calcium level, and
M-component levels in serum and urine. Response to chemotherapy and patient survival are also significantly correlated with the measured myeloma cell burden ${ }^{3}$. Hematologic monitoring in multiple myeloma is based on determination of the serum and urine levels of paraprotein, albumin, hemoglobin, creatinine, and calcium.

Conventional radiological imaging is a method for staging multiple myeloma as well as for assessing complications of the skeletal system. Both multidetector CT and MRI are recommended for mid- and long-term monitoring ${ }^{5)}$. The combined use of multidetector CT and MRI is also useful for initial staging of multiple myeloma ${ }^{10)}$. 1.5 tessler whole body STIRMRI can detect bone marrow infiltration in about $74 \%$ of multiple myeloma patients. Moreover, whole-body MRI showed a diagnostic accuracy superior to that of multislice computed tomography. In particular, the early stages of disease with less prominent osteolytic changes and diffuse infiltration patterns are more reliably visualized with the use of $\mathrm{MRI}^{16}$. The involvement of $>10$ bone marrow focal points and diffuse infiltration on MRI are more risky factors to predict vertebral fractures ${ }^{6}$. Both FDG-PET in combination with lowdose CT and whole-body MRI are more sensitive than skeleton X-ray in screening and diagnosing multiple myeloma. However, whole-body MRI is less suitable in assessing response to therapy than FDG-PET ${ }^{9)}$.

Vertebroplasty provides significant and long-lasting pain relief and reduces the risk of fracture or new collapse in contiguous vertebral bodies. Vertebroplasty is an effective treatment that confers pain relief, enhanced mobility, and reduced use of medicine for all the stages of multiple myeloma associated with compression fracture ${ }^{12)}$. Vertebroplasty was also confirmed in patients experiencing pain related to malignant spinal tumors with epidural extension, with a low complication rate ${ }^{15)}$.

\section{CONCLUSION}

We should check for the possibility of pathologic vertebral fractures from multiple myeloma in non-osteoporotic compre- 
ssion fracture patients, especially when continuous fractures are present in relatively non-elderly patients, even though a history of trauma may exist. Vertebroplasty is an effective method to relieve pain in cases of vertebral compression fracture due to malignancy.

\section{REFERENCES}

1. Astolfi S, Scaramuzzo L, Logroscino CA: A minimally invasive surgical treatment possibility of osteolytic vertebral collapse in multiple myeloma. Eur Spine J 18:115-121, 2009

2. Basile A, Cavalli M, Fiumara P, Di Raimondo F, Mundo E, Caltabiano G, et al: Vertebroplasty in multiple myeloma with osteolysis or fracture of the posterior vertebral wall. Usefulness of a delayed cement injection. Skeletal Radiol 40:913-919, 2011

3. Durie BG, Salmon SE: A clinical staging system for multiple myeloma. Cancer 36:842-854, 1975

4. Garland P, Gishen P, Rathemtulla A: Percutaneous vertebroplasty to treat painful myelomatous vertebral deposits-longterm efficacy outcomes. Ann Hematol 90:95-100, 2011

5. Horger M, Weisei K, Bares R, Ernemann U, Claussen CD, Lichy $\mathrm{M}$, et al: Modern imaging techniques during therapy in patients with multiple myeloma. Acta Radiol 52:881-888, 2011

6. Lecouvet FE, Malghem J, Michaux L, Michaux JL, Lehmann F, Maldague BE, et al: Vertebral compression fractures in multiple myeloma. Part II. Assessment of fracture risk with MR imaging of spinal bone marrow. Radiology 204:201-205, 1997

7. Lecouvert FE, Vande Berg BC, Maldaque BE, Michaux L, Laterre E, Michaux JL, et al: Vertebral compression fractures in multiple myeloma. Part I. Distribution and appearance at MR imaging. Radiology 204:195-199, 1997
8. Lim BS, Chang UK, Youn SM : Clinical outcomes after percutaneous vertebroplasty for pathologic compression fractures in osteolytic metastatic spinal disease. J Korean Neurosurg Soc 45:369-374, 2009

9. Lutje S, de Rooy JW, Croockewit S, Koedam E, Oyen WJ, Raymakers RD: Role of radiography, MRI and FDG-PET/CT in diagnosing, staging and therapeutical evaluation of patients with multiple myeloma. Ann Hematol 88:1161-1168, 2009

10. Mahnken AH, Wildberger JE, Gehbauer G, Schmitz-Rode T, Blaum M, Fabry U, et al: Multidetector CT of the spine in multiple myeloma: comparison with MR imaging and radiography. AJR Am J Roentgenol 178:1429-1436, 2002

11. Masala S, Anselmetti GC, Marcia S, Massari F, Manca A, Simonetti G: Percutaneous vertebroplasty in multiple myeloma vertebral involvement. J Spinal Disord Tech 21:344-348, 2008

12. McDonald RJ, Trout AT, Gray LA, Dispenzieri A, Thielen KR, Kallmes DF: Vertebroplasty in multiple myeloma: outcomes in a large patient series. AJNR Am J Neuroradiol 29: 642-648, 2008

13. Papaionnou A, Watts NB, Kendler DL, Yuen CK, Adachi JD, Ferko N: Diagnosis and management of vertebral fractures in elderly adults. Am J Mes 113:220-228, 2002

14. Park JH, Kim TS, Jeong JH, Koh JS, Lim YJ, Kim GK, et al: Rapidly progressive multiple myeloma involving whole spine in a young adult. Korean J Spine 2:165-167, 2005

15. Saliou G, Kocheida el M, Lehmann P, Depriester C, Paradot G, Le Gars D, et al: Percutaneous vertebroplasty for pain management in malignant fractures of the spine with epidural involvement. Radiology 254:882-890, 2010

16. Schmidt GP, Kramer H, Reiser MF, Glaser C: Whole-body magnetic resonance imaging and positron emission tomography-computed tomography in oncology. Top Magn Reson Imaging 18:193-202, 2007 